\title{
Short-term changes of meiofaunal abundance in intertidal sediments
}

\author{
Werner Armonies \\ Biologische Anstalt Helgoland, Wattenmeerstation Sylt; D-W-2282 List, Germany
}

\begin{abstract}
Some species of various meiofaunal taxa may actively emerge from the sediment and swim in the water column, preferably at night. In the water column they get dispersed by tidal currents. The hypothesis that this drift may cause significant short-term changes in the abundance of these species was tested. Such changes were verified for harpacticoid copepods and plathelminths. Depending on the hydrographic conditions, abundance changes may be unpredictable or show regularly alternating patterns. In the light of these results, small-scale spatial estimates of abundance become generally very difficult to make in the taxa containing emergent species. It is suggested that reliable averages can only be obtained by repeated or large-scale spatial sampling.
\end{abstract}

\section{INTRODUCTION}

During recent years, the traditional view that meiobenthos is exclusively restricted to life in the sediment has been constantly revised. Members of all the major benthic taxa have been found in the water column, and at least the better swimmers among harpacticoid copepods and plathelminths may actively leave the sediment (see review by Palmer, 1988). It seems that active swimming occurs primarily during night-time (Alldredge \& King, 1980; Hammer, 1981; Fulton, 1984; Walters \& Bell, 1986; Walters, 1988; Arlt, 1988).

Once in the water column, benthic swimmers are subject to dispersal by tidal currents and the direction of the currents will determine the direction of transportation. For an intertidal habitat with semidiurnal tides, this means that a nocturnal ebb tide will cause an offshore transport of benthic swimmers, and a nocturnal flood tide an onshore transport. Onshore dispersal should increase the abundance of swimmers in the upper intertidal, and decrease abundance in the lower intertidal (unless the losses are compensated for by immigration from shallow subtidal sites). The reverse should occur during nocturnal ebb tides when offshore transport of swimmers occurs.

During a phase of constancy in overall abundance, small-scale patches are expected to show an alternating pattern of high and low abundance depending on the current direction during the preceding nights. Respective alternating patterns may also be expected during periods of seasonal population growth or decline when local abundance is compared with overall abundance as estimated by regression.

This study was designed to look for the described variations in the local abundance of meiobenthic swimmers in the sediment. It should be noted, however, that the above 
model represents an ideal situation in assuming a rather constant direction of the ebb and flood tides. Wind driven currents may change the direction of the tidal currents and thus cause rather unpredictable imports or exports of specimens. In addition, gales may erode the sediment and associated fauna. This should likewise result in unpredictable changes of abundance. Strictly regular patterns of weekly alternating abundances over many weeks can therefore at best be expected during periods with very calm weather conditions. Finally, it should be noted that regular sampling can only reveal net changes of abundance which exceed small-scale spatial variability. The used sampling design cannot give an estimate of the swimming activity of a species, i.e. the percentage of a population which has entered the water column.

According to the available data, species differ in the set of environmental conditions that favour their active water-column entrance. They thus differ in the timing of both emergence and sediment re-entry (Walters, 1988; Decho, 1988; Armonies, 1988a, b, 1989a, b; Bell et al., 1989). Therefore, no general pattern can be expected for all species of benthic swimmers. Even worse, in analyses based on higher taxonomic levels, the abundance variations of single species may compensate each other, resulting in no significant overall effect. Therefore, whenever possible, studies on meiofaunal behaviour should be based on species.

\section{MATERIAL AND METHODS}

Between July 6th and September 18th 1989, sediment samples were collected from an intertidal sandflat area near the Island of Sylt in the northern Wadden Sea (North Sea). A general description of the area is given by Reise (1985). Tides are semidiurnal and average tidal range is $1.8 \mathrm{~m}$. Two sites of $5 \times 10 \mathrm{~m}$ were sampled regularly at about weekly intervals (Fig. 1). Site I (upper intertidal) was located seaward of the mean high tide level at neap tides and site II (lower intertidal) landward of the mean neap low tide level. Water depth during mean high tide was about $0.5 \mathrm{~m}$ at site I and $1.5 \mathrm{~m}$ at site II. The two plots were about $250 \mathrm{~m}$ apart in a W-E direction (Fig. 1). Tidal currents have approximately the same directions and the prevailing westerly winds do not significantly change the direction of the tidal currents. Southern winds are rather ineffective because of a dike at the southern border of the studied area. However, because of the same dike northern winds may change the tidal currents in an unpredictable manner.

At the upper intertidal site the sediment consists of well sorted medium sand (median diameter of sand grains $383 \mu \mathrm{m}$, sorting coefficient 1.52; $\mathrm{cf}$. Schmidt, 1968). The sediment of the lower intertidal site was less well sorted and finer (median diameter $303 \mu \mathrm{m}$, coefficient of sorting 1.98). The silt content was smaller than $0.3 \%$ of dry weight at both sites. From both sites, two sets of samples were collected at each of the ten sampling dates; first, ten cores of $2 \mathrm{~cm}^{2} / 0-5 \mathrm{~cm}$ which were sorted for plathelminths, and secondly, ten cores of $1 \mathrm{~cm}^{2} / 0-5 \mathrm{~cm}$ which were fixed in $10 \%$ formalin for later enumeration of copepods, nematodes, and sediment analyses. At each site the replicate samples were collected at random. However, when the sediment surface was rippled, care was taken to collect the same amount of crests and troughs.

The sampling dates were fixed using a tide table to select the next low tide after a series of preceding nocturnal ebbing or flooding waters (Table 1, Fig. 2). Plathelminthes were extracted from the sediment samples using a shaking-decantation procedure 


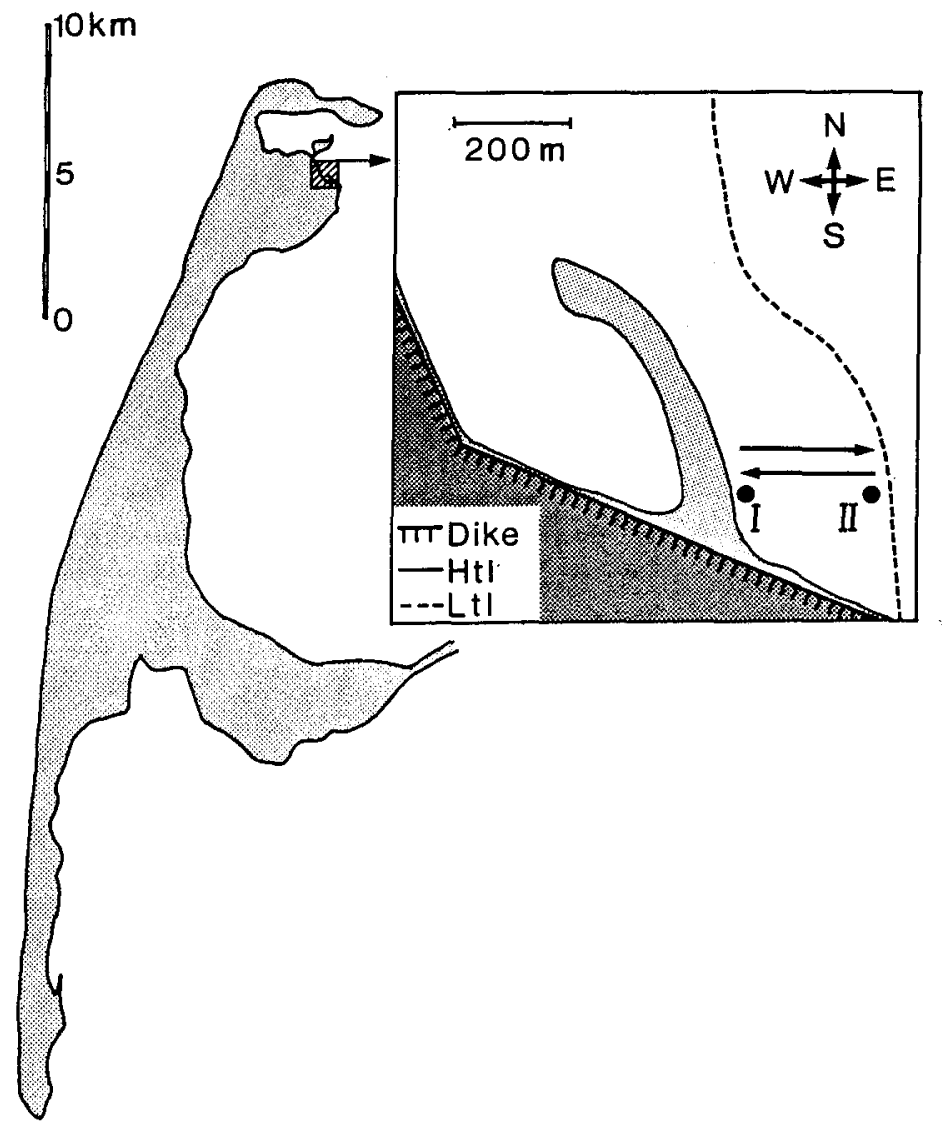

Fig. 1. Location of the sampled sites (I, II) in the Wadden area near the Island of Sylt (North Sea). Arrows indicate the prevailing direction of the tidal currents

(Armonies \& Hellwig, 1986), and determined alive to species level. The same method of extraction was applied to the formalin-fixed samples. Nematodes were counted, and in harpacticoids the 5 most abundant species were determined to species level and all other species pooled to "others". The sediment of each of the 200 samples fixed was wet sieved, oven dried, and weighted. Calculation of the median diameter of sand grains and the coefficient of sorting was according to Schmidt (1968).

Abundance data generally showed significant deviations from a normal distribution. Therefore, non-parametric statistical methods were used, all according to Sachs (1984). Using the data given in Armonies (1989a), plathelminth species are classified into either "swimmers" (i.e. species which have been shown to emerge actively from the sediment in rather high abundance) and non-swimmers (i.e. species which have rarely, or never, been found swimming in the water column). 


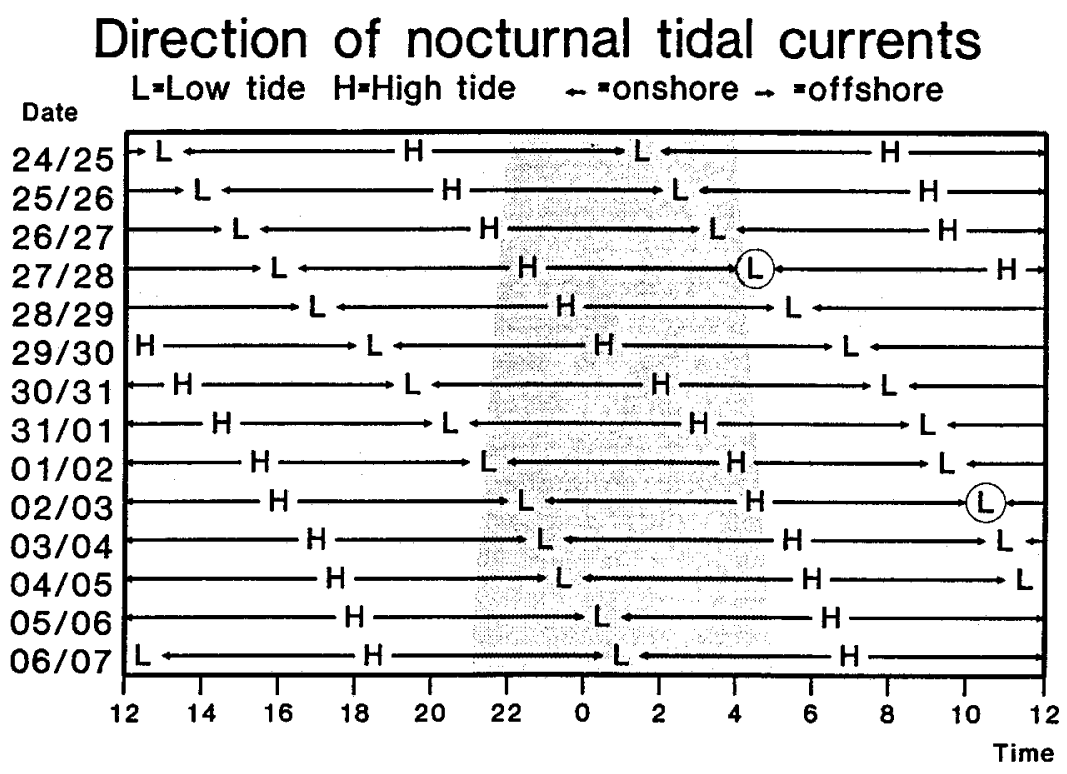

Fig. 2. Direction (onshore or offshore) of the nocturnal tidal currents between July 25 th and August 6 th. Samples were collected when a high or low tide coincided with sunrise (July 28 and August 3). Each terminated a series of nights with prevailing onshore or offshore tidal currents. Dotted area: period between sunset and sunrise

Table 1. Sampling dates, direction of tidal currents during the preceding nights, and unusual weather conditions

\begin{tabular}{|clll|}
\hline No. & Date & $\begin{array}{c}\text { Direction of the } \\
\text { tidal currents }\end{array}$ & $\begin{array}{c}\text { Unusual weather } \\
\text { conditions }\end{array}$ \\
\hline 1 & July 6 & onshore & - \\
2 & July 13 & onshore & NW storm * \\
3 & July 19 & offshore & N wind \\
4 & July 28 & onshore & calm \\
5 & August 3 & onshore & calm \\
6 & August 14 & offshore & calm \\
7 & August 28 & onshore & calm \\
8 & September 4 & onshore & NNE storm \\
9 & September 11 & & E wind \\
10 & September 18 & & - \\
& prevented sample collection & & \\
\hline
\end{tabular}




\section{RESULTS}

\section{Harpacticoidea and Cyclopoidea}

Abundances of harpacticoids and cyclopoids (mainly Cyclopina rotundipes Herbst, 1952; cf. Mielke, 1976) vary considerably. This is especially true when their abundance is compared with the moderate fluctuations of nematode abundance (Fig. 3). At the lower

\section{Upper intertidal}

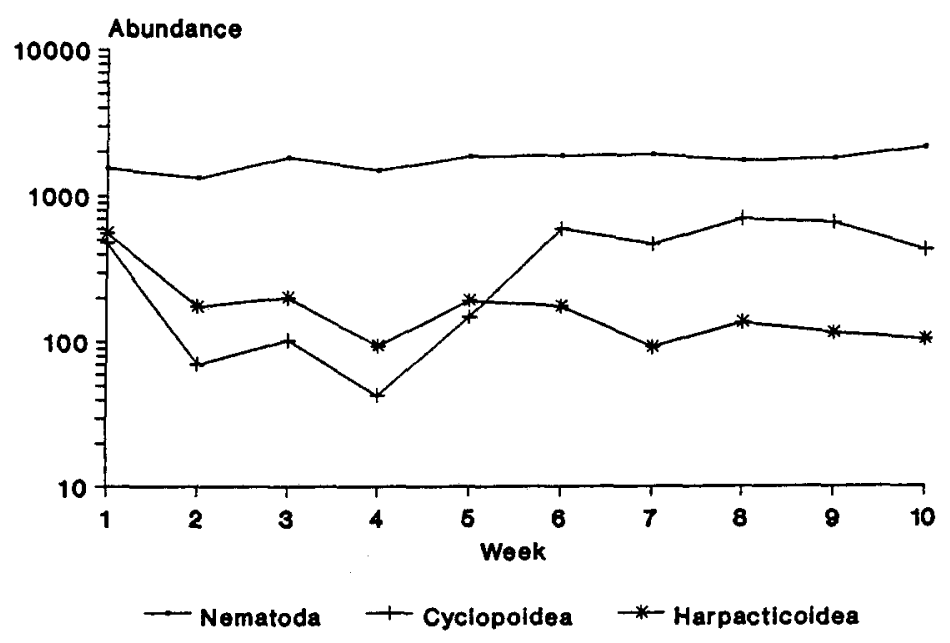

\section{Lower intertidal}

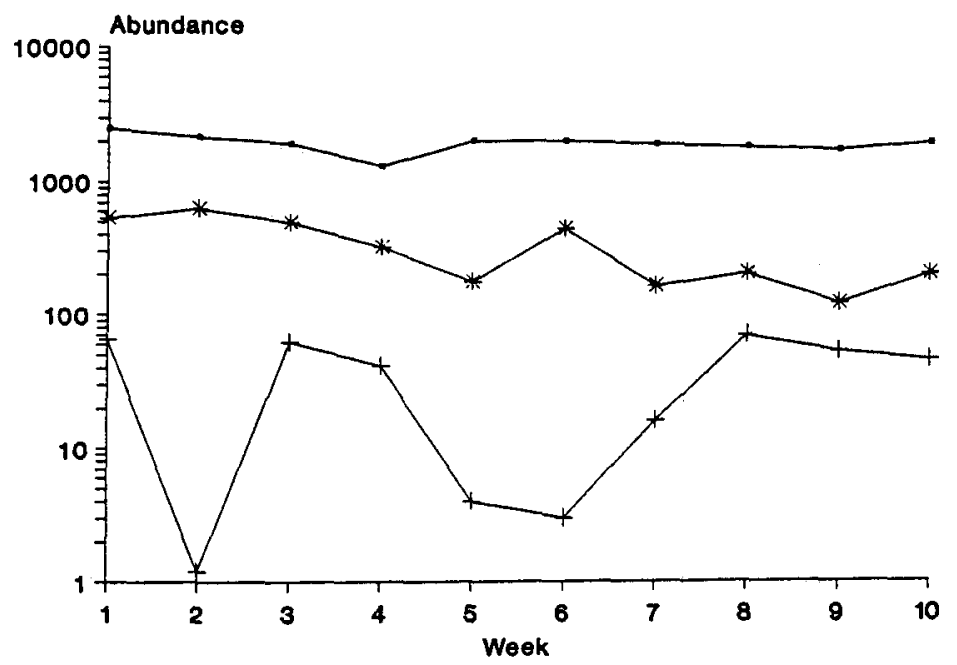

Fig. 3. Variability of the nematode, cyclopoid, and harpacticoid abundances per $10 \mathrm{~cm}^{2}$ over 10 weeks in summer 1989 
intertidal site, cyclopoid numbers were too low (always $<100 \cdot 10 \mathrm{~cm}^{-2}$ ) to allow a statistical evaluation. At the upper intertidal site, the changes in abundance between two consecutive sampling dates are strikingly parallel in cyclopoids and harpacticoids. In 8 out of 9 comparisons, the changes have the same tendency (Fig. 4). The probability of such a parallelism occurring by chance is well below 0.05 (binominal distribution, $p$ $<0.0176)$.

\section{Comparison with preceding week Upper intertidal}

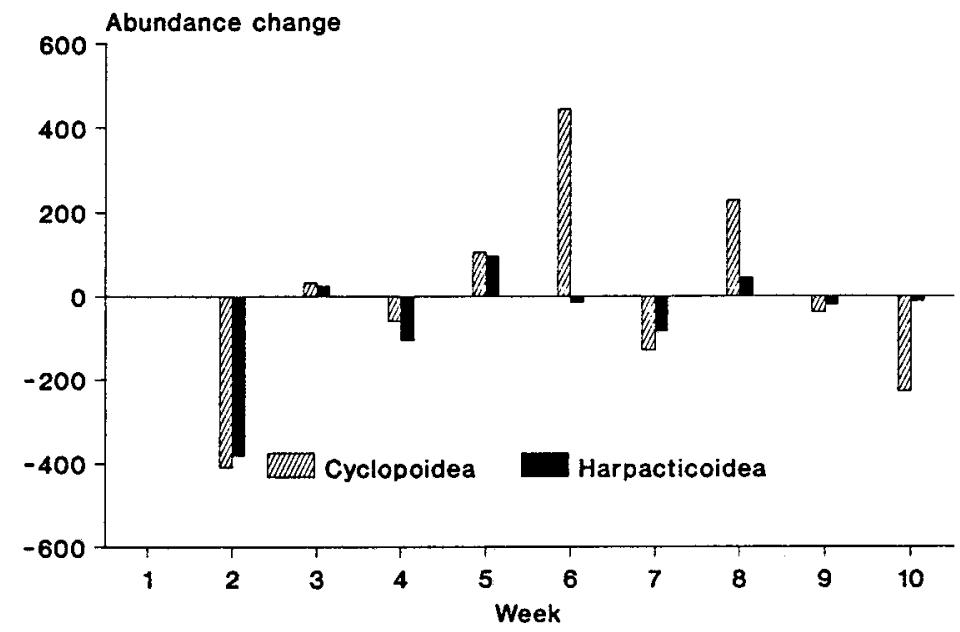

Fig. 4. Abundance changes of cyclopoids and harpacticoids on consecutive sampling dates. With a single exception, both taxa show the same tendencies of change

It seems that abundance changes in the two taxa depend, at least in part, on the same factors. Considering the narrow time scale of this study, the parallelism may be due to either common drift of individuals with the tidal currents, or a preference for the same type of microhabitat (which might have been sampled in a varying number of replicate samples). However, in only 3 of the 10 sampling dates was there a significant positive correlation of abundances in the replicate samples (Spearman rank correlation coefficient, $\mathrm{p}<0.05$ ). Since members of both taxa predominantly live at the sediment surface and hence are subject to the same type of microspatial habitat disturbance, a weak correlation was expected. Preference for the same type of microhabitats cannot explain the parallelism of abundance variations.

Cyclopina rotundipes were mainly copepodites. The significant increase in abundance during the second half of this study may therefore be due to reproductive events, although this cannot explain alternating abundance changes between consecutive sampling dates. The harpacticoid assemblage was dominated by Harpacticus flexus Brady \& Robertson, 1873 , which accounted for $47 \%$ of harpacticoid abundance, followed by Asellopsis intermedia (T. Scott, 1895) with $20 \%$. Abundances of Nitocra typica Boeck, 1864 (8\%), Amphiascoides debilis (Giesbrecht, 1881) (6\%), Tachidius discipes Giesbrecht, $1881(5 \%)$, and others were too low for a statistical evaluation. 


\section{Harpacticus flexus}

In the upper intertidal, $H$. flexus was very abundant at the first sampling date but abundance dropped by an order of magnitude during the gale between sampling dates 1 and 2. Abundance was too low, then, for a statistical evaluation. In the lower intertidal, abundance of $H$. flexus showed a seasonal decrease (Spearman rank correlation coefficient, $\mathrm{r}=-0.855, \mathrm{p}<0.01$ ). Since the intermittent gale significantly changed abundance in the upper intertidal, the first sampling date is left out in the further analysis of the lower intertidal abundance because abundance changes during the gale might be due to passive erosion instead of active swimming.

The seasonal decrease in the lower intertidal abundance is described by regression models. An exponential model fitted the measured data best (Chi-square test of goodness of fit, chi-square $=0.27, \mathrm{~N}=9$ ). The abundances at the sampling dates 2,3 , and 4 are in good agreement with the regression in showing an average deviation of expected abundance smaller than $5 \%$ (Fig. 5). However, at the final 6 sampling dates, abundance in the field deviated on an average by $70 \%$ from the predictions of the model. Positive and negative deviations do regularly alternate (Fig. 5). The probability of such an alternation occurring just by chance is well below $5 \%$ (binominal distribution, $p=0.5$, $\mathrm{n}=6$ ). Whenever the preceding nocturnal tidal currents had an onshore direction, abundance in the field was higher than expected, and vice versa. Obviously, onshore currents imported specimens from shallow sublittoral sites and offshore currents exported individuals from the tidal flats. In no case was there a correlation between abundance or abundance change and a sediment property (median diameter of sand grains, sorting coefficient), neither between averages of sampling dates nor between the replicates of single dates.

\section{Asellopsis intermedia}

Abundance of $A$. intermedia was low in the upper intertidal but tended to increase over time (Spearman rank correlation coefficient, $r=+0.721, p<0.05$ ). Abundance was higher in the lower intertidal (Fig. 6) but there was no monotonous temporal trend. The abundance variations may be explained by reproductive activity during these summer months (cf. Mielke, 1976). Deviations from a linear regression model show no striking regular pattern and are small enough to be explained by random variations between replicate samples. Thus there is no reference to a significant net drift of $A$. intermedia caused by tidal currents.

\section{Plathelminthes}

Abundance of Plathelminthes showed no significant trend during this study with the exception of an increase in abundance of a single species, Pogaina suecica Luther, 1948, which reproduced in the upper intertidal area (Spearman rank correlation coefficient, total $\mathrm{r}=+0.47, \mathrm{p}>0.05 ;$. suecica $\mathrm{r}=+0.939, \mathrm{p}<0.001$ ). In the further analysis, this species is left out.

Despite the lack of a significant constant trend in the remaining 53 plathelminth species, abundance varies significantly over time in both the upper and lower intertidal sites $(\mathrm{H}$-tests, $\mathrm{p}<0.05 ;$ Fig. 7). Abundance variations are significant for swimmers (H-test, $\mathrm{p}<0.01$ ), while non-swimmer abundances are compatible with the hypothesis of random deviations from an overall mean $(\mathrm{H}$-test, $\mathrm{p}>0.05)$. The temporal variance of swimmer 


\section{Harpacticus flexus lower intertidal}

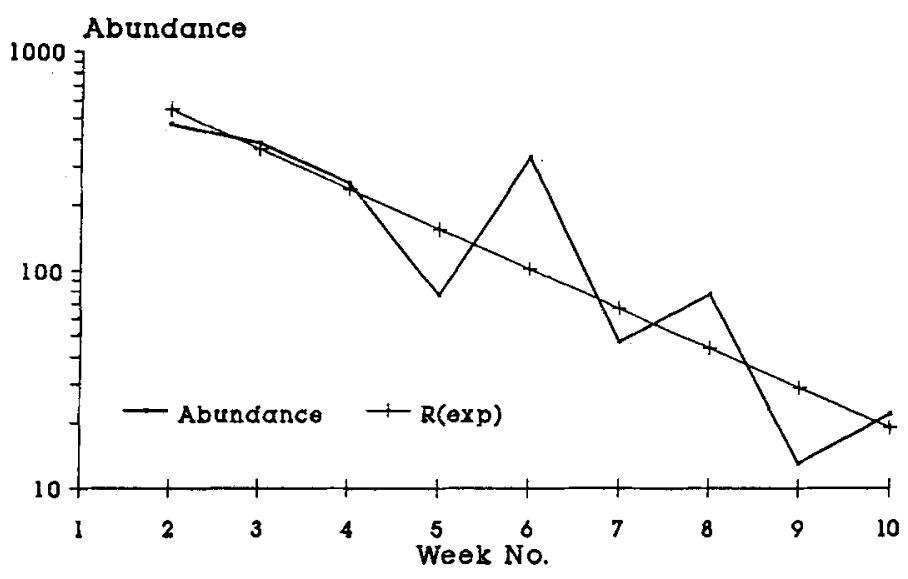

Percentage deviation from regression

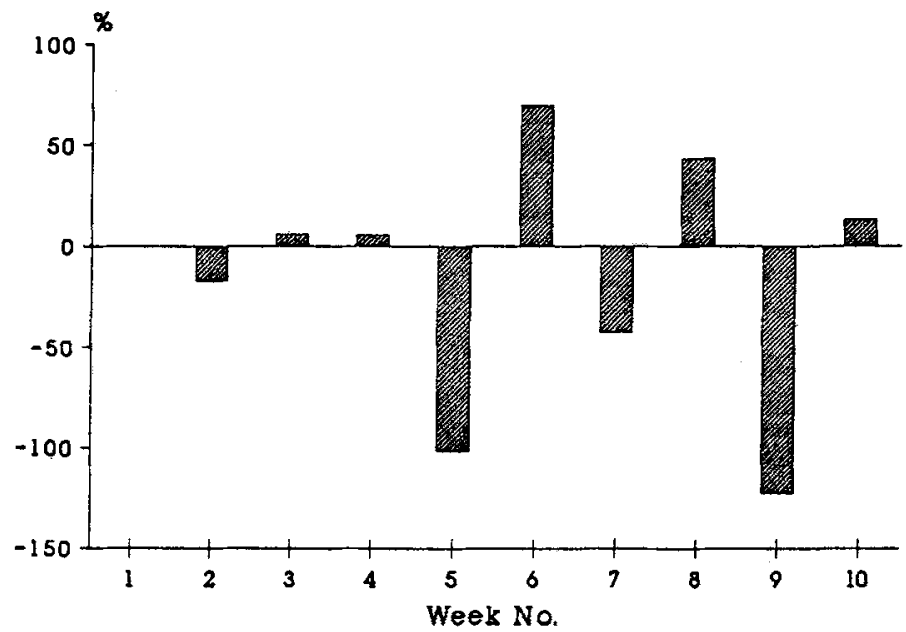

Fig. 5. Abundance of $H$. flexus in the lower intertidal sediment and the best fitted regression line (above). In the final 7 sampling dates, the percentage deviations from the regression alternate regularly (below)

abundances is significantly higher than the non-swimmer variance of abundance $\left(\mathrm{F}_{\max }{ }^{-}\right.$ test, $F=36.39, p<0.01$; lower intertidal). In plathelminth swimmers the changes of abundance between two consecutive sampling events correlate in the upper and lower intertidal sites (Wilcoxon matched pair signed rank statistics, $R=2, n=8, p<0.05$ ). Nonswimmer abundance changes, in contrast, are independent of each other at the two tidal levels $(R=21, n=9, p>>0.05)$. 


\section{Asellopsis intermedia lower intertidal}

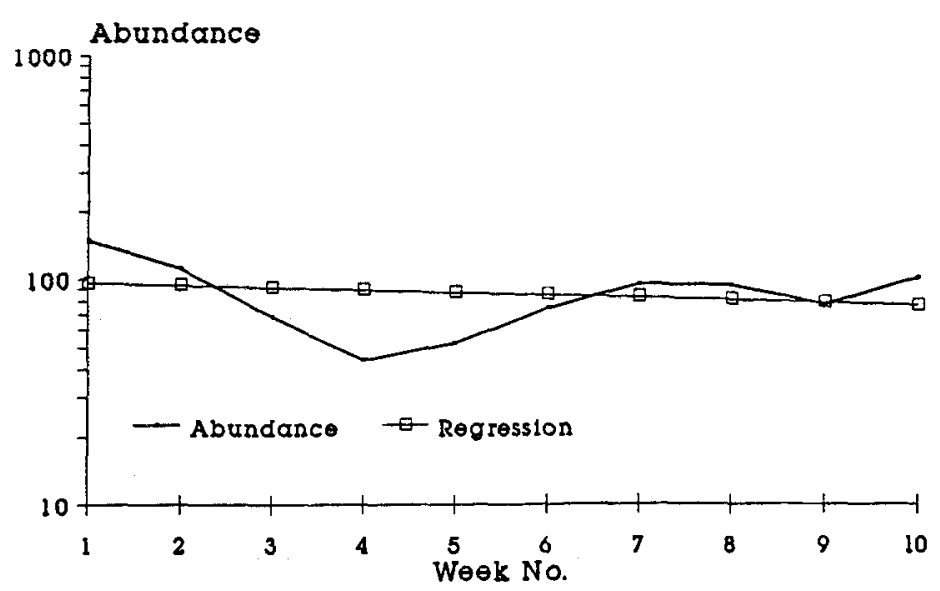

Percentage deviation from regression

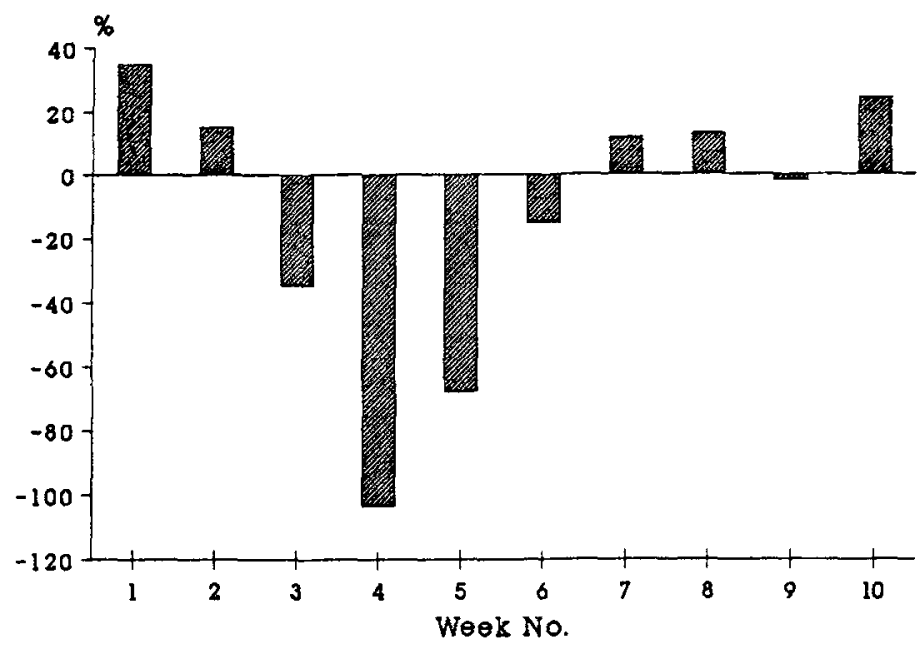

Fig. 6. Abundance of $A$. intermedia in the lower intertidal sediment. The percentage deviations from the regression line do not correlate with tidal currents

\section{DISCUSSION}

The percentage of a population that actively emerges from the sediment and swims in the water column is species-specific and modified by both abiotic and biotic factors (Walters, 1988; Decho, 1988; Armonies, 1988a, b, 1989b; Bell et al., 1989). Roughly classifying the plathelminth species into swimmers and non-swimmers (Armonies, 1989a) 


\section{Plathelminthes Upper intertidal}

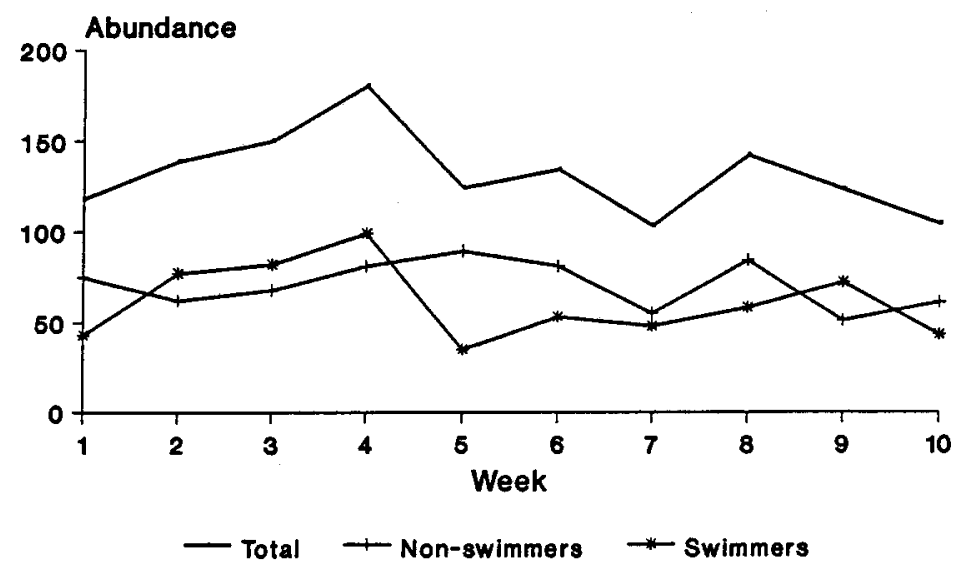

Lower intertidal

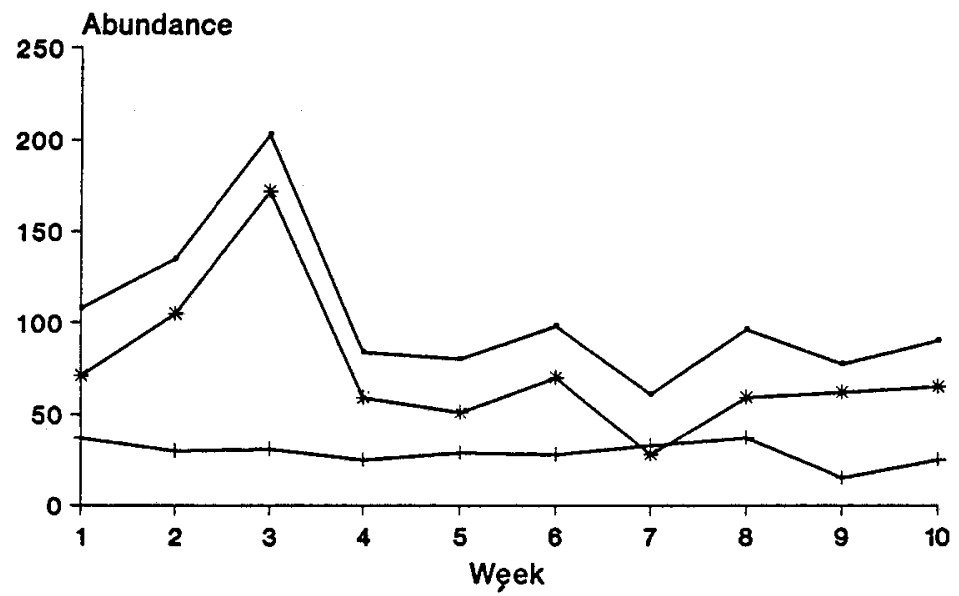

Fig. 7. Plathelminth abundance in the upper and lower intertidal sites. Abundance of non-swimming species is less variable than swimmer abundance

yielded two assemblages of species with statistically significant differences in behaviour. Non-swimmer abundance was less variable than swimmer abundance, and abundance variations of non-swimmers were independent of each other at the two tidal levels. This was expected of benthic species in the traditional sense. However, the rather low variability of abundances only refers to a scale of time, not space. On a small spatial scale, non-swimmers were as patchily distributed as were swimmers although the causes of patchiness may be different. 
The behaviour of plathelminth swimmers, on the other hand, deviated significantly from traditional benthic behaviour in their showing short-term abundance changes that cannot be explained by patchiness (Fig. 8). Within a few days, abundance varied over an order of magnitude without any reproductive activity or mortality. As a consequence, a comparison of the plathelminth abundance at the two tidal levels would have resulted in

\section{Plathelminthes* Lower intertidal}

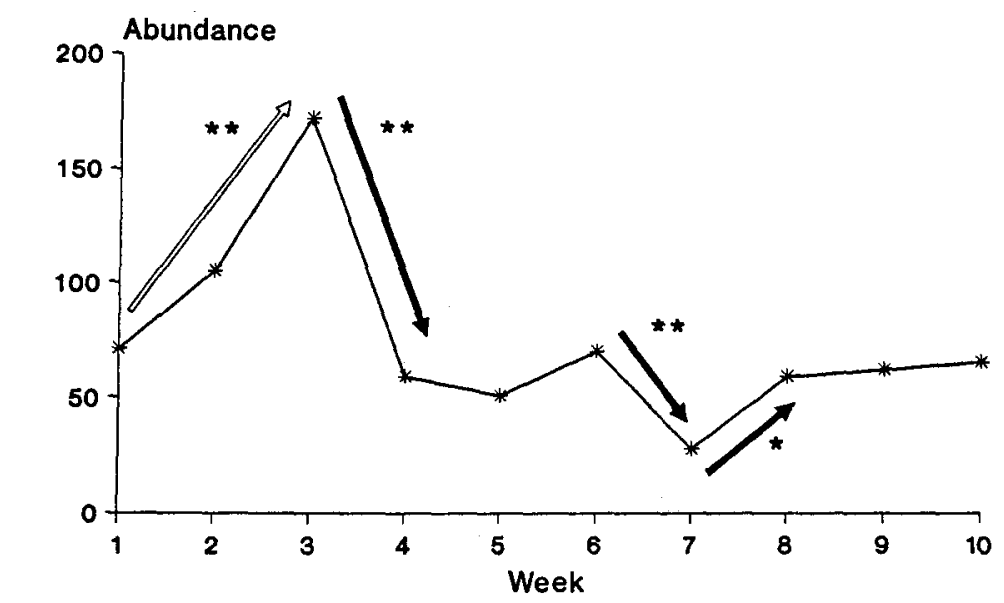

- without Pogaina sueciga

Fig. 8. Statistically significant short-term changes of plathelminth abundance in the lower intertidal site (U-test, " $p<0.05, \cdots p<0.01$ ). Abundance changes are mainly due to swimming species (see Fig. 7)

"no significant difference" at 5 of the sampling dates and in a statistical significant difference at the other dates. In Harpacticus flexus, the situation is similar (6 times significant, 4 times not). Likewise, density fluctuations between years may in part result from migrations (Arlt, 1988), and migrations may result in daily variation of the microdistribution, patchiness, and species composition (Alldredge \& King, 1980). Thus, without consideration of the high mobility of some species, results of both descriptive and experimental studies may be highly erroneous.

The possible causes of water column entrance vary between species, and include flight from unfavourable biotic (Service \& Bell, 1987) or physical (Armonies, 1988b) factors prevailing in the sediment, usage of the tidal current for dispersal (Decho, 1988), and utilization of the water column habitat itself, e.g. for mating (Bell et al., 1987) or exploitation of food resources (Decho, 1986). In any case, the emergent fauna will be redistributed over a (presumably, species-specific) wide area. Therefore, a single set of sediment samples can only yield a snap-shot of the small-scale spatial abundance which might be strongly changed the tide after. Concerning meiofaunal taxa including emergent species, it is suggested that reliable estimates of abundance can be obtained in one of 3 ways depending on the matter of interest: (1) For an estimate of the total population 
abundance, samples need to be simultaneously collected over the entire area of distribution. (2) For small-scale spatial studies, replication in time is neccessary. (3) Since the total area of distribution is often unknown and simultaneous collection of many samples hampered by restricted time, personal, and sampling device, I especially suggest a combination of (1) and (2) in replicating sample collection both in time and space over the spatial and temporal scales of interest.

\section{LITERATURE CITED}

Alldredge, A. L. \& King, J. M., 1980. Effects of moonlight on the vertical migration pattern of demersal zooplankton. - J. exp. mar. Biol. Ecol. 44, 133-156.

Arlt, G., 1988. Temporal and spatial meiofauna fluctuations in an inlet of the south west Baltic (Darss-Zingst Bodden Chain) with special reference to the Harpacticoida (Copepoda, Crustacea). - Int. Revue ges. Hydrobiol. 73, 297-308.

Armonies, W., 1988a. Hydrodynamic factors affecting behaviour of intertidal meiobenthos. Ophelia 28, 183-193.

Armonies, W., 1988b. Physical factors influencing active emergence of meiofauna from boreal intertidal sediment. - Mar. Ecol. Prog. Ser. 49, 277-286.

Armonies, W., 1989a. Semiplanktonic Plathelminthes in the Wadden Sea. - Mar. Biol. 101, 521-527.

Armonies, W. $1989 \mathrm{~b}$. Meiofaunal emergence from intertidal sediment measured in the field: significant contribution to nocturnal planktonic biomass in shallow waters. - Helgoländer Meeresunters. 43, 29-43.

Armonies, W. \& Hellwig, M., 1986. Quantitative extraction of living meiofauna from marine and brackish muddy sediments. - Mar. Ecol. Prog. Ser. 29, 37-43.

Bell, S. S., Hicks, G. R. F. \& Walters, K., 1989. Experimental investigations of benthic reentry by migrating meiobenthic copepods. - J. exp. mar. Biol. Ecol. 130, 291-303.

Bell, S. S., Walters, K. \& Hall, M. O., 1987. Habitat utilization by harpacticoid copepods: a morphometric approach. - Mar. Ecol. Prog. Ser. 35, 59-64.

Decho, A. W., 1986. Water-cover influences on diatom ingestion rates by meiobenthic copepods. Mar. Ecol. Prog. Ser. 33, 139-146.

Decho, A. W., 1988. How do harpacticoid grazing rates differ over a tidal cycle? Field verification using chlorophyll-pigment analyses. - Mar. Ecol. Prog. Ser 45, 263-270.

Fulton, R. S., 1984. Distribution and community structure of estuarine copepods. - Estuaries 7, 38-50.

Hammer, R. M., 1981. Day-night differences in the emergence of demersal zooplankton from a sand substrate in a kelp forest. - Mar. Biol. 62, 275-280.

Mielke, W., 1976. Ökologie der Copepoda eines Sandstrandes der Nordseeinsel Sylt. - Mikrofauna Meeresboden 59, 1-86.

Palmer, M. A., 1988. Dispersal of marine meiofauna: a review and conceptual model explaining passive transport and active emergence with implications for recruitment. - Mar. Ecol. Prog. Ser. $48,81-91$.

Reise, K., 1985. Tidal flat ecology. Springer, Berlin, $191 \mathrm{pp}$.

Sachs, L., 1984. Angewandte Statistik. Springer, Berlin, 552 pp.

Schmidt, P., 1968. Die quantitative Verteilung und Populationsdynamik des Mesopsammon am Gezeiten-Sandstrand der Nordseeinsel Sylt. I. Faktorengefüge und biologische Gliederung des Lebensraumes. - Int. Revue ges. Hydrobiol. 53, 723-779.

Service, S. K. \& Bell, S. S., 1987. Density-influenced active dispersal of harpacticoid copepods. - J. exp. mar. Biol. Ecol. 114, 49-62.

Walters, K., 1988. Diel vertical migration of sediment associated meiofauna in subtropical sand and seagrass habitats. - J. exp. mar. Biol. Ecol. 117, 169-186.

Walters, K. \& Bell, S. S., 1986. Diel patterns of active vertical migration in seagrass meiofauna. - Mar. Ecol. Prog. Ser. 34, 95-103. 